\title{
MOOCs as Disruptive Innovation in Higher Education
MOISN
}

\author{
Kamarudin Hussin \\ Chairman University Management Board \\ Universiti Malaysia Perlis, Malaysia \\ Email: kamarudin@unimap.edu.my
}

\section{INTRODUCTION}

The advancement of technology in higher education is always perceived as a valuable innovation that create better impact to the society. The advent of the Internet for instance, has magnificently created important features in learning environment globally. Higher education community optimizes the Internet as an essential resource, communication platforms and dynamic tools in their core teaching-learning, research, consultation activities, entertainment and many others. Moreover, innovations such as mobile technology has successfully broadened access to the Internet and related online services and facilities. Higher education institutions as the hub for technology development and innovation have invested in virtual learning environment to support current needs of global population. Related to this fact, elearning modules and contents are offered across universities, and interested learners in public communities are benefited by this opportunity. Educators and experts in higher education institutions are delivering their knowledge, discoveries and expertise via e-learning platforms and other supported technology. Equally important, e-learning has successfully expanded opportunities for lifelong and flexible learning, and offered a solution for practical issues and increasing student numbers. As a matter of fact, e-learning has been proposed as a promising way out for many complex issues such as funding constraints, increasing demand and access to higher education while improving quality and high impact educational provisions in many countries. While addressing these issues, higher education administrators, educators, researchers and policy makers have developed responses in various frameworks. Initiatives such as Competency-Based Online Programs, development of open source materials, flipped classroom and Massive Open Online Courses (MOOCs) have contributed towards reducing cost of higher education as well as increasing access to higher education. MOOCs technology has proven its capability to reach massive audience of about 30,000 students at a time. Across the globe, MOOCs offer free access to online course lectures, selfpaced lessons, readings, problem sets, blogs, discussion boards, peer assessment and even online discussion group platforms for global students (Leon and Price, 2016). In 2017, MOOCs offered more than 9,400 courses with more than 500 MOOC based credentials according to data gathered by Class Central. Excitingly, MOOC platforms have recorded more than 81 million learners to date (Class Central, 2017).

\section{MOOCs AND DISRUPTIVE INNOVATION}

The broad spectrum of discussion on MOOCs as a disruptive innovation in higher education lies on its potential to replace traditional location-based education. This includes possible serious transformation and alteration of the structure of teaching and learning activities that are currently taking place in formal education (Blin and Munroe, 2008). Opinions arisea mong educators on how online education namely MOOCs will affect traditional on-campus instructional delivery method in a setting of brick-and-mortar universities. At the same time, faculty, administrators and instructional designers are concerned on the possibility of MOOCs as disruptive forces in transformation of higher education ecosystems. Faculty members often view MOOCs as a negative disruption that threatens their connection with students and leaves them few meaningful roles in a digitized, outsourced higher education landscape (Leon and Price, 2016). 


\section{AUPF.}

However, educational technologies in general are required by educators to support traditional modes of teaching by improving the quality of contents delivery in traditional classroom setting. Over the years, disruption in higher education incorporated other segments beyond teaching learning, such as resource provision, dynamic communication platforms, courses design and assessments, external compliance requirements, accreditations, dynamic and effective contents delivery platforms, and many others. These scenarios incorporated challenges of disruptive technologies to university administrators and students population.

\section{MOOCs AND DISRUPTIVE INNOVATION}

The arguments whether MOOCs is a disruptive technology in higher education become an important research question investigated by researchers across the globe. In view of disruption in education, it refers to a serious transformation or alteration of the structure of teaching and learning activities taking place in formal education (Blin and Munroe, 2008). Another interesting point to highlight is the adoption of disruptive innovation theory to analyse whether MOOCs are really disruptive innovations in higher education. Christensen and Horn (1995) defined disruptive innovation as a process by which a product or service takes root initially in simple applications at the bottom of a market and then relentlessly moves up market, eventually displacing established competitors. The justification of whether or not MOOCs can be disruptive to higher education is based on three main criteria and questions. Is MOOCs managed to open up markets by competing with the existing structure of university using low-cost business models? At present, do MOOCs successfully improve the delivery of higher education and its various components beyond the level of existing universities? The last question focuses on the capacity of MOOCs to improve quality and ultimately replace established universities and their present ecosystems. Looking at those specific guidelines, Langen and Van de Bosch (2013) concluded that MOOCs will not be the disruptive innovations that have been predicted by some and hoped by others, but they will (among the greater ODL family) be facilitators of other developments that could change the educational sector.

\section{MOOCs AS SUSTAINABLE ONLINE EDUCATION}

MOOCs offers dynamic and effective technology to reach mass student population as influenced by the cause of education liberalization and democratization. Educators and administrators in higher education sector must be mindful that MOOCs and online education can be transformed to a sustaining technology. As such, educators and administrators were seen to be obliged to contribute towards the enhancement of MOOCs as a sustaining technology. Although MOOCs are commonly believed by educators to bring disruptive influences to the traditional university programs, innovative and entrepreneurial leaders have successfully discover new opportunities towards a sustainable solutions. Some world-class and reputable universities such as Stanford University have elevated MOOCs to a higher level which turns out to be and impactful initiative. Statistics recorded more than 10 million learners around the world have enrolled in Stanford's free MOOCs

(VPTL,https://news.stanford.edu/2018/06/22/moocs/). In the case of Stanford University, the faculty members optimize MOOCs technology to spread their knowledge, expertise and scholarship to a broader audience. Faculty members will always be challenged to continue searching for the means and ways to stay relevant in their role as educators. 